\title{
Endüstride Yaygın Olarak Kullanılan Asit Çözeltileri İçinde AA5754 Yüzeyinin ve Korozyon Davranışının İncelenmesi
}

\section{Investigation of Surface and Corrosion Behaviour of AA5754 in Acid Solutions Commonly Used in Industry}

\author{
Erhan Karaca ${ }^{1}$, Engin Alkan ${ }^{2}$ \\ Geliş / Received: 09/08/2021 \\ Revize / Revised: 11/10/2021 \\ Kabul / Accepted: 22/10/2021
}

\section{$\overline{\text { öZ }}$}

Çeşitli uygulama alanlarında elektrolit olarak kullanılabilecek borik asit $\left(\mathrm{H}_{3} \mathrm{BO}_{3}\right)$, tartarik asit (TA), okzalik asit $\left(\mathrm{H}_{2} \mathrm{C}_{2} \mathrm{O}_{4}\right)$, hidroklorik asit $(\mathrm{HCl})$, hidroflorik asit $(\mathrm{HF})$ ve tetrafloroborikasitin $\left(\mathrm{HBF}_{4}\right)$ sulu çözeltileri içinde alüminyum 5754 alaşımının (AA5754) korozyon çalışmaları gerçekleştirilerek ortamdaki asit niteliğinin aliminyum oksit oluşumu üzerine etkisi birbiriyle karşılaştırılarak incelenmiştir. Asitlerde bekletilen AA5754 yüzeyi XRD, XPS, AFM ve profilometre yöntemleri ile karakterize edilmiştir. XRD sonuçları $\mathrm{Al}_{2} \mathrm{O}_{3}$ oluşumunu gösterirken XPS sonuçları bu oluşumun doğrulanmasının yanında spektrumda $\mathrm{B}, \mathrm{O}, \mathrm{C}, \mathrm{Cl}$ ve $\mathrm{F}$ piklerinin gözlenmesi nedeniyle asitlerin yüzeye adsorblandığına işaret etmiş̧tir. AFM ve profilometre görüntülerinden $\mathrm{H}_{3} \mathrm{BO}_{3}$, TA ve $\mathrm{H}_{2} \mathrm{C}_{2} \mathrm{O}_{4}$ ortamlarında elde edilen oksit tabakalarının $\mathrm{HCl}$, $\mathrm{HF}$ ve $\mathrm{HBF}_{4}$ 'dekilere göre daha düzgün topografyaya sergilediği belirlenmiştir. Tüm asitler karşılaştırıldığında $\mathrm{H}_{3} \mathrm{BO}_{3}$ ortamında en düşük pürüzlülük değerlerine $(24.28 \mathrm{~nm})$ sahip, homojen ve en kalın $(15.4 \mathrm{~nm})$ oksit filmin oluştuğu belirlenirken $\mathrm{HBF}_{4}$ ortamında tam tersidir (sırasıyla $99.44 \mathrm{~nm}$ ve $0.64 \mathrm{~nm}$ ). AA5754 numunesinin korozyon davranışı asit çözeltileri içinde OCP, Tafel ve EIS ölçümleri ile incelenmiştir. Buna göre $\mathrm{HBF}_{4}, \mathrm{HF}, \mathrm{HCl}, \mathrm{H}_{2} \mathrm{C}_{2} \mathrm{O}_{4}$, TA ve $\mathrm{H}_{3} \mathrm{BO}_{3}$ siralamasıyla OCP değerleri pozitif potansiyellere kaymakta, $\mathrm{i}_{\mathrm{kor}}$ değerleri azalmakta ve $\mathrm{R}_{\mathrm{ct}}$ değerleri artmaktadır. AA5754 numunesi $\mathrm{HF}$ ve $\mathrm{HBF}_{4}$ ortamlarında diğerlerine göre çok farklı bir korozyon davranışı sergilediği gözlenmiştir. Bunun nedeni $\mathrm{HBF}_{4}{ }^{\prime}$ ün sulu ortamda kısmi ayrışması sonucu üretilen $\mathrm{HF}$ sayesinde yüzeyde $\mathrm{AlF}_{6}^{-{ }^{-3}}$ kompleksinin oluşumu ile çözünmenin daha fazla gerçekleşmesi olmalıdır. Tersine, $\mathrm{H}_{3} \mathrm{BO}_{3}$ 'te ortaya çıkan oksit tabakası, korozyona karşı en etkili yüzeyi sağlamıştır, çünkü diğerlerine göre zayıf asidik karakteri $\left(\mathrm{pK}_{\mathrm{a}}=9.27\right)$ nedeniyle çekirdeklenme ve ardından pasivasyon çok hızlı gerçekleşmektedir.

Anahtar Kelimeler- Endüstriyel Asit, Alüminyum Alaşım, Alüminyum Oksit, Yüzey Karakterizasyonu, Korozyon

\footnotetext{
ABSTRACT

Corrosion studies of aluminum 5754 alloy (AA5754) immersed in aqueous solutions which could be used as electrolytes in various application areas were carried out. The effect of acid type on the aluminum oxide formation was investigated for boric acid $\left(\mathrm{H}_{3} \mathrm{BO}_{3}\right)$, tartaric acid (TA), oxalic acid $\left(\mathrm{H}_{2} \mathrm{C}_{2} \mathrm{O}_{4}\right)$, hydrochloric acid $(\mathrm{HCl})$, hydrofluoric acid $(\mathrm{HF})$, and tetrafluoroboric acid $\left(\mathrm{HBF}_{4}\right)$ by comparing with each other. AA5754 surface was characterized by XRD, XPS, AFM, and profilometer methods. While $\mathrm{Al}_{2} \mathrm{O}_{3}$ formation was determined in XRD

1*Sorumlu yazar iletişim: erhankaraca@hacettepe.edu.tr (https://orcid.org/0000-0002-9100-8870) Kimya Bölümü, Hacettepe Üniversitesi, Fen Fakültesi, Ankara, Türkiye Iİletişim: enginalkn@gmail.com(https://orcid.org/0000-0002-5933-3147) Kimya Bölümü, Hacettepe Üniversitesi, Fen Fakültesi, Ankara, Türkiye
} 
results of all acids, it was confirmed the $\mathrm{Al}_{2} \mathrm{O}_{3}$ formation in the XPS spectra and indicated that the acids were adsorbed on the surface due to the presence of $\mathrm{B}, \mathrm{O}, \mathrm{C}, \mathrm{Cl}$, and $\mathrm{F}$ peaks. According to the AFM and profilometer images, it was determined that the oxide layers obtained in $\mathrm{H}_{3} \mathrm{BO}_{3}$, TA, and $\mathrm{H}_{2} \mathrm{C}_{2} \mathrm{O}_{4}$ media exhibited a more uniform topography than those in $\mathrm{HCl}, \mathrm{HF}$, and $\mathrm{HBF}_{4}$. When all acids were compared, it was determined that the homogeneous and thickest $(15.4 \mathrm{~nm})$ oxide film with the lowest roughness values $(24.28 \mathrm{~nm})$ was formed in the $\mathrm{H}_{3} \mathrm{BO}_{3}$ medium, while the results obtained in $\mathrm{HBF}_{4}$ were the opposite (99.44 nm and $0.64 \mathrm{~nm}$, respectively). The corrosion behavior of the AA5754 sample was investigated by OCP, Tafel, and EIS measurements in acid solutions. Accordingly, it was determined that OCP values shifted to the positive potentials, $\mathrm{i}_{\text {corr }}$ values decreased, and $\mathrm{R}_{\mathrm{ct}}$ values increased in the order of $\mathrm{HBF}_{4}, \mathrm{HF}, \mathrm{HCl}, \mathrm{H}_{2} \mathrm{C}_{2} \mathrm{O}_{4}$, TA, and $\mathrm{H}_{3} \mathrm{BO}_{3}$. It was found that the AA5754 specimen exhibited different corrosion behavior in $\mathrm{HF}$ and $\mathrm{HBF}_{4}$ media compared to the others. The reason should be the formation of the $\mathrm{AlF}_{6}^{-3}$ complex due to $\mathrm{HF}$ produced as a result of the partial decomposition of $\mathrm{HBF}_{4}$ in the aqueous medium. Thus, the dissolution of aluminum carried out much more. Conversely, the oxide layer formed in $\mathrm{H}_{3} \mathrm{BO}_{3}$ provided the most effective surface against corrosion. It was because the nucleation and subsequent passivation occurred very rapidly thanks to its weak acidic character $\left(\mathrm{pK}_{\mathrm{a}}=9.27\right)$ relative to the others.

Keywords- Industrialacid, Electrolyte, Aluminum Alloy, Aluminum Oxide, Surface Characterization, Corrosion

\section{GíRiș}

Düşük yoğunlukta olup iyi mekanik özellik gösteren ve yüksek korozyon direncine sahip malzemelerin gerektiği endüstri uygulamalarında 5xxx serisi alüminyum alaşımları yaygın olarak kullanılmaktadır [1]. Özellikle alüminyum alaşımları enerji depolama sistemlerinde korozyon dayanımları nedeniyle tercih edilen malzemelerden biridir [2]. Alüminyum ve alaşımlarının yüzeyinde doğal olarak, homojen olmayan ince bir alüminyum oksit filmi oluşur ve bu tabaka malzemenin korozyon dayanımına direkt olarak etki etmektedir [3]. Bu nedenle literatürde oksit tabakasının kalitesini iyileştirmek üzerine birçok çalışma vardır. Li ve ark. [3], yaptığı bir çalışmada pillerde

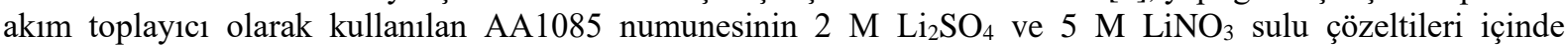
elektrokimyasal kararlılı̆̆ incelenmiş ve kalın bir oksit tabakası oluşumu sayesinde yüzeyde meydana gelen çukurcuk korozyonunu inhibe ettiği ortaya çıkarılmıştır. $\mathrm{pH}$, anodik potansiyel ve anyon çeşidine bağlı olarak bu bileşiklerin adsorpsiyon mekanizması çalışılmış ve sülfat iyonları alüminyum pasif filmine adsorbe olurken nitratın olmadığı belirlenmiştir. Başka bir araştırmada AA6060 numunesi yüksek sıcaklıkta sitrik asit ve fosforik asit buharına maruz bırakılarak yüzeyde büyüyen oksit tabakası incelenmiştir[4]. Oksit tabakası oluşumunun alaşımın yapısına, kullanılan aside ve ortamın pH'na bağlı olduğu bulunmuştur. Sitrat iyonları alüminyum sitrat oluşturarak alüminyumun çözünmesini arttırması ve intermetalik bölgelerde daha fazla çekirdeklenme olması nedeniyle yüzeyde daha kalın bir oksit tabakası oluşturduğu ve korozyona karşı dayanım gösterdiği belirlenmiştir. Fosfat varlığında ise daha ince bir oksit tabakası oluştuğu ortaya çıkarılmıştır. Bunun nedeni ise fosfat anyonlarının, daha kararlı olan ve yüzeyin hidratasyonunu geciktiren komplekslerin oluşması ve böylece oksit oluşumunun azalmasıdır.

Eloksal süreci alüminyum alaşımlarına uygulanan etkili korozyon koruma işlemlerinden biridir ve yüzeyde kalın bir oksit tabakası oluşumuna neden olur. Bu tabaka, alkali veya asidik ortamda hazırlanmasından bağımsız olarak aynı kimyasal özelliklere sahip olup içte bariyer ve dışta poroz tabakaları içerir. Bariyer tabakası ince ve yoğunken, poroz tabaka $10^{3}-10^{4}$ kat daha kalındır. $\mathrm{H}_{3} \mathrm{BO}_{3}$ varlığında anodizasyonla oluşturulan oksit tabakasının gözenek boyutunun daha az olduğunu, sonuçta malzemenin korozyon direncini arttırdığını tespit edilmiştir [5]. Ban ve ark. [6], tarafından yapılan bir çalışmada borik asit ve borik asit+sitrik asit karışımının daha yüksek derecede kristaliniteye sahip bir bariyer film elde etmeye yardımcı olabileceği gösterilmiştir. Stancin ve Douglas'ın yaptığ 1 bir patent çalışmasında $\mathrm{H}_{2} \mathrm{SO}_{4}$ ve $\mathrm{H}_{3} \mathrm{BO}_{3}$ içeren çözeltide anodizasyon işlemi sonucunda 30$800 \mathrm{mg} / \mathrm{ft}^{2}$ kaplama yapılmış ve korozyon korumasını arttırdığı belirlenmiştir [7]. Başka bir çalışmada AA5005 alaşımının $\mathrm{H}_{3} \mathrm{PO}_{4}$ ve $\mathrm{H}_{3} \mathrm{BO}_{3}$ elektrolit karışımında anodize edilmesiyle korozyon direncinin arttığı bildirilmiştir [8]. Sadece $\mathrm{H}_{3} \mathrm{PO}_{4}$ içeren çözeltide anodize edildikten sonra oluşturulan alüminyum oksit filmi yüksek porozitede olup incedir, $\mathrm{H}_{3} \mathrm{BO}_{3}$ ile elde edilen film ise yüksek korozyon direncine sahiptir. Saeedikhani ve ark. [9], çalışmasında alüminyum alaşımını $\mathrm{H}_{2} \mathrm{SO}_{4}, \mathrm{H}_{3} \mathrm{BO}_{3} \mathrm{ve}_{3} \mathrm{HO}_{4}$ banyosunda anotlaştırılması ile elde edilen nispeten kalın filmin korozyon direncini geliştirdiği gösterilmiştir. Diğer bir çalışmada, AA2024-T3 alaşımı $10 \% \mathrm{H}_{2} \mathrm{SO}_{4}$, $5 \% \mathrm{H}_{3} \mathrm{BO}_{3}$ ve $2 \% \mathrm{H}_{3} \mathrm{PO}_{4}$ içerisinde anotlaştırılmış ve mühürleme (sealing) işlemi yapılmıştır [10]. $\mathrm{H}_{2} \mathrm{SO}_{4}$ ile karşılaştırıldığında, oksit tabakasının daha kalın ve elektrolit emilimine karşı daha yüksek direnç gösterdiği 
bildirilmiştir. Mert ve ark. [11], çalışmasında $\mathrm{H}_{2} \mathrm{SO}_{4}$ ve $\mathrm{H}_{3} \mathrm{BO}_{3}$ içeren çözeltide $15 \mathrm{~V}$ 'de alüminyum alaşımı anotlaştırılmış ve korozyon davranış $3.5 \% \mathrm{NaCl}$ içinde incelenmiştir. Homojen bariyer oksit filmine $\mathrm{H}_{2} \mathrm{BO}_{3}^{-}$, $\mathrm{HBO}_{3}{ }^{2-}, \mathrm{BO}_{3}{ }^{3-}, \mathrm{HSO}_{4}^{-}$, ve $\mathrm{SO}_{4}{ }^{2-}$ türlerinin katılması sayesinde korozyon direncinin anlamlı bir şekilde arttı̆̆ belirlenmiştir. AA2024 yüzeyinde adipik asit kullanılarak üretilen anodik oksit filmin korozyon direnci araştırılmıştır [12]. Bu asitin elektrolit/anodik tabaka ara yüzeyine adsorplandığı, anodik tabakanın çözünmesini azalttığı ve neticede film kalınlı̆̆ındaki artış yüzünden korozyon hızını azalttığı sonucuna varılmıştır.

Elektolitik kapasitör uygulamaları ile ilgili bir çalışmada, anodizasyon işlemi $\mathrm{H}_{3} \mathrm{BO}_{3}$ ve TA varlığında gerçekleştirildiğinde kristalin oksit filmin oluşumunun desteklendiği ve filmin kapasitesinin arttığı gösterilmiştir [6]. Bununla birlikte ani faz değişimi sonucu büzülmelere bağlı olarak oluşan boşlukların yüzeyde çatlaklara neden olduğu, bunun da filmin direncini ve dayanımını azalttığı sonucuna ulaşılmıştır. Surganov ve ark. [13], çalışmasında TA içinde oksit film oluşumu ve çekirdekleşme kinetiği araştırılmıştır. Oksit hücrelerinin tane sınırları boyunca oluştuğu ve anodizasyon potansiyeli arttıkça oluşan oksit hücre sayısının ve çapının arttı̆ğ gösterilmiştir. Yatışkan halde (daldırma durumunda) hücre boyutu artarken, sayısı 1,5 kat azalmıştır. Marzocchi ve ark. [10] çalışmasında AA2024 alaşımının anodizasyonunu TA içeren $\mathrm{H}_{2} \mathrm{SO}_{4}$ çözeltisinde gerçekleştirdiklerinde morfoloji ve dielektrik davranışları $\mathrm{H}_{2} \mathrm{SO}_{4}$ ile anodize edilene benzemesine rağmen gözenek dirençlerinde büyük artış belirlenmiştir. Ma ve ark. [14], çalışmasında aynı çözelti karışımında AA2099-T8 alaşımının anodizasyonununda düşük voltajlarda düzenli yapıda gözenekli oksit filmi oluşurken artan voltajlarda büyük boyutlarda düzensiz gözenekli oksit filmler elde edildiği bildirilmiştir. Boisier ve ark. [6], çalışmasında da aynı karışımda AA2024 anodizasyonunu gerçekleştirdikten sonra yüksek sıcaklıkta mühürleme işleminin ardından korozyona dirençli oksit tabakalarının oluştuğu gösterilmiştir. Bunun nedeni olarak yüksek sıcaklıkta mühürlemenin poroziteyi azalttı̆̆ bildirilmiştir.

Choudhary ve ark. [15], çalışmasında $\mathrm{H}_{2} \mathrm{C}_{2} \mathrm{O}_{4}$ çözeltisinde gerçekleştirilen anodizasyon ile oluşturulan oksit tabakasına uygulanan voltajın çizilme hasarına, kimyasal bileşimine, yüzey morfolojisine, yüzey topografyasına ve elektriksel direncine etkisi incelenmiştir. Yüksek anodizasyon voltajında daha hızlı çözünmeye bağlı olarak gözenekli ve pürüzlü alüminyum oksit tabakası oluştuğu belirtilmiş̧tir. Keshavarz ve ark. [16], çalışmasında ise $\mathrm{H}_{2} \mathrm{SO}_{4}, \mathrm{H}_{2} \mathrm{C}_{2} \mathrm{O}_{4}$ ve bunların karışımını içeren çözeltide poroz alümina şablon anodize edilmiş ve $\mathrm{H}_{2} \mathrm{SO}_{4}$ de gözenek boyutu küçük, boşluk yoğunluğunun yüksek olduğu; $\mathrm{H}_{2} \mathrm{C}_{2} \mathrm{O}_{4}$ içinde ise gözenek dağılımının daha düzenli olduğu ortaya çıkarılmıştır. Gözenek çaplarının sıcaklıkla, uygulanan voltajla ve tavlamayla da kontrol edilebileceği gösterilmiştir.

Madakson ve ark. [17], çalışmasında AA7075 alaşımının $\mathrm{HCl}$ ortamında anodizasyonunun korozyon davranışı üzerine etkisi incelenmiştir. $\mathrm{Cl}^{-}$iyonlarının oksit filme bölgesel olarak ciddi bir şekilde zarar vermesi sonucu ciddi seviyede aşınma olmakla birlikte anodize edilmiş örneklerde korozyon hızının azaldığı gösterilmiştir. Hidrojen çıkışı yüzünden pH'ın bölgesel artı̧ı ile veya hava etkisi ile oluşan filmin protonlanarak çözünmesi ve ardından çökelmesi mekanizmasıyla yüzeyde oksit filmi meydana geldiğini açıklamışlardır. Başka bir çalışmada $\mathrm{HCl}$ içeren çözeltide alüminyum numunesine giderek artan voltajlar uygulanarak çukurcuk oluşturma davranışı incelenmiştir [18]. Çukurcuklar, hava ile oluşan oksit filmindeki kusurlara asidin saldırmasıyla meydana gelir ve oluşan bir yığın çukurcuk birleşerek büyük çukurcuklara neden olur. $\mathrm{HBF}_{4}$ içeren çözeltide anodizasyon işleminin gerçekleştirildiği çalışmada ise yüksek gözenekliliğe sahip oksit tabakası elde edilmiştir[18]. Bu ortam, yüksek potansiyeller ve yüksek akım yoğunluğu gerektirdiğinden küçük ölçekli çalışmalar için uygun olduğu önerilmiştir.

Aluminyum endüstrisinde anodizasyon proseslerinde asitler arasında en çok $\mathrm{H}_{3} \mathrm{BO}_{3}$ [5,8,11], TA $[6,10,13,14]$ ve $\mathrm{H}_{2} \mathrm{C}_{2} \mathrm{O}_{4}[16]$, tercih edilmekte ve araştırmalar genellikle bu alanda gerçekleştirilmektedir. $\mathrm{Bu}$ çalışmada literatürden farklı olarak alüminyum alaşımlarının bulunduğu ortamlarda elektrolit olarak kullanılabilme potansiyeli olan bazı asit çözeltilerinde oluşan oksit tabakasının özellikleri ve korozyon davranışları araştırılarak birbirleriyle karşılaş̧ırması yapılmıştır. Öncelikle $0.1 \mathrm{M} \mathrm{H}_{3} \mathrm{BO}_{3}, \mathrm{TA}, \mathrm{H}_{2} \mathrm{C}_{2} \mathrm{O}_{4}, \mathrm{HCl}, \mathrm{HF}$ ve $\mathrm{HBF}_{4}$ çözeltilerine daldırılıp bekletme yoluyla AA5754 yüzeyinde kendiliğinden oluşan oksit tabakalı yüzeyler XPS, AFM ve profilometre yöntemleri ile karakterize edilmiştir. Daha sonra asit çözeltileri içerisinde AA5754 numunesinin korozyon davranışları incelenerek birbiriyle karşılaştırılmıştır. Korozyon testleri için açık devre potansiyeli (OCP), elektrokimyasal empedans spektroskopisi (EIS) ve Tafel yöntemleri kullanılmıştır.

\section{MATERYAL VE METOT}

Elektrokimyasal ölçümler 3 elektrotlu hücrede gerçekleştirilmiştir. Referans ve karşı̂t elektrot olarak sırasıyla SCE ve Pt spiral elektrotlar kullanılmışır. Çalışma elektrodu olarak alüminyum 5754 alaşım (AA5754) disk $\left(0.07065 \mathrm{~cm}^{2}\right)$ ve levha $\left(1.00 \mathrm{~cm}^{2}\right)$ elektrotlar kullanılmıştır. AA5754 bileşiminde ağırlıkça \%0.099 $\mathrm{Si}, \% 0.267 \mathrm{Fe}, \% 0.001 \mathrm{Cu}, \% 0.006 \mathrm{Mn}, \% 2.113 \mathrm{Mg}, \% 0.002 \mathrm{Cr}, \% 0.007 \mathrm{Zn}, \% 0.001 \mathrm{~Pb}, \% 0.013 \mathrm{Ti}, \% 0.009 \mathrm{Zr}$ 


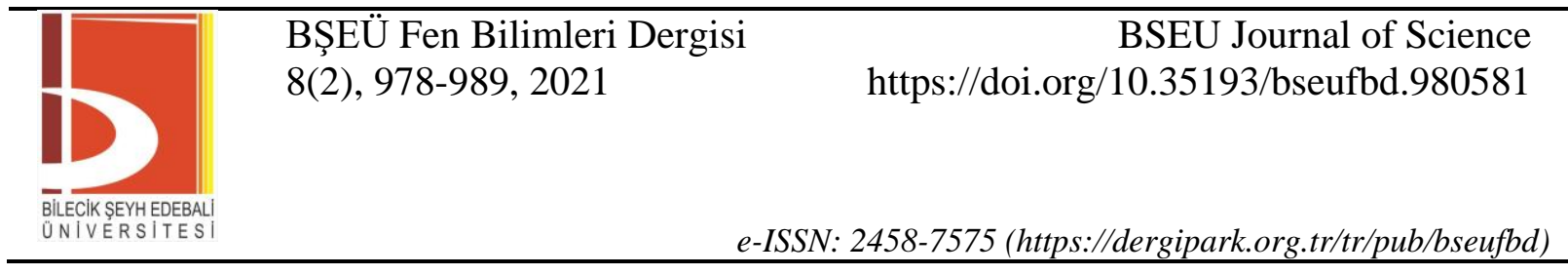

ve \%97.46 Al bulunmaktadır. Her deneyden önce AA5754 elektrodun yüzeyi sırasıly 800, 1000, 1200 ve 2000 taneli zımparayla parlatıldıktan sonra etanol/su karışımı ile üç kez yıkanmıştır.

Karakterizasyon çalışmaları için önce AA5754 levha elektrodu 0.1 M H $\mathrm{H}_{3} \mathrm{BO}_{3}, \mathrm{TA}, \mathrm{H}_{2} \mathrm{C}_{2} \mathrm{O}_{4}, \mathrm{HCl}, \mathrm{HBF}_{4}$ ve HF çözeltilerine daldırılmış ve kararlı oksit tabakasının oluşumunu sağlamak için bir saat bekletilmiştir. Daha sonra elde edilen yüzeylerin XRD ve XPS spektrumları ile AFM ve profilometre görüntüleri alınmıştır. AA5754 numunesinin korozyon davranışının incelenmesi, her bir asidin 0.1 M çözeltisi içerisinde OCP, EIS ve Tafel teknikleri kullanılarak gerçekleştirilmiştir.

XRD analizi PANalytical, Empyrean X-ray difraktometresi, XPS analizi Specs-Flex X-ray fotoelektron spektrometresi cihazları ile gerçekleştirilmiştir. AFM ölçümleri için Asylum Research MFP-3D spektrometresi ve Profilometre ölçümleri için KLA Tencorstylus profilometre cihazları kullanılmıştır. Korozyon testleri Gamry (Reference 3000) ve CHInstruments 6011D potansiyostat/galvanostat cihazları ile yapılmıștır. Açık devre potansiyeli (OCP) ölçümleri 6 saat süreyle kaydedilmiştir. EIS ölçümleri OCP'de $1.00 \times 10^{5}$ den $1.00 \times 10^{-1} \mathrm{~Hz}$ frekans aralığında $5.00 \mathrm{mV}$ genlikte gerçekleştirilmiş̧ir. Elde edilen EIS ölçümleri ile uyumlu olan eşdeğer devre modeli ve elemanları ZSimpwin V3.50 yazılımı (Scribner AssociatesInc.) kullanılarak belirlenmiştir. Tafel eğrileri $1 \mathrm{mV} \mathrm{s}^{-1}$ tarama hızında kaydedilmiştir.

\section{SONUÇLAR VE TARTIŞMA}

Endüstride yaygın olarak kullanılan $\mathrm{H}_{3} \mathrm{BO}_{3}, \mathrm{TA}, \mathrm{H}_{2} \mathrm{C}_{2} \mathrm{O}_{4}, \mathrm{HCl}$ ve $\mathrm{HBF}_{4}$ sulu çözeltilerinde alüminyum alaşımlarının anodizasyon çalışmaları bulunmakla birlikte $[5-8,10,11,13,14,16-19]$ bu asitlerin bulunduğu ortamlarda oluşan alüminyum oksit filminin karakterizasyonu ve malzemenin korozyon davranışı henüz incelenmemiş̧ir. Ayrıca HF'nin sulu ortamında alüminyum alaşımları ile ilgili hiçbir çalışma bulunmamaktadır. Özellikle enerji depolama aygıtlarında kullanılan alüminyum folyoların korozyonu pilin ömrünü önemli ölçüde sınırlamaktadır. Bu nedenle elektrolit olarak kullanılabilecek çeşitli asitlerin varlı̆̆ında alüminyum alaşımının korozyon davranışını incelemek ve birbiriyle karşılaştırmak önem kazanmaktadır. Bu araştırmanın ilk aşamasında, yüzeyi temizlenmiş alüminyum 5754 alaşımı (AA5754) $0.1 \mathrm{M} \mathrm{H}_{3} \mathrm{BO}_{3}, \mathrm{TA}, \mathrm{H}_{2} \mathrm{C}_{2} \mathrm{O}_{4}, \mathrm{HCl}, \mathrm{HF}$ ve $\mathrm{HBF}_{4}$ çözeltilerine daldırıldıktan sonra numune yüzeyi karakterize edilmiş ve ikinci aşamasında korozyon davranışı incelenmiştir.

\section{A. Çeşitli Asitlerin Bulunduğu Ortamda AA5754 Yüzeyinin Karakterizasyonu}

1) XRD: X-ışını kırınımı spektroskopisi (XRD) ile $0.1 \mathrm{M} \mathrm{H}_{3} \mathrm{BO}_{3}, \mathrm{TA}, \mathrm{H}_{2} \mathrm{C}_{2} \mathrm{O}_{4}, \mathrm{HCl}$, HF ve $\mathrm{HBF}_{4}$ çözeltilerine maruz kalmış AA5754 yüzeyinin spektrumları alınmıştır. Spektrumlar incelendiğinde piklerin asit türüne göre değiş̧iklik göstermediği belirlenmiş, bu nedenle Şekil 1'de sadece $\mathrm{H}_{3} \mathrm{BO}_{3}$, TA ve $\mathrm{H}_{2} \mathrm{C}_{2} \mathrm{O}_{4}$ 'e ile ilgili spektrumlar sunulmuştur. Buna göre $38.6^{\circ}, 44.8^{\circ}, 65.3^{\circ}$ ve $78.3^{\circ}$ de gözlenen şiddetli pikler Al'ye (ICDD pdf \#: 01-089-3657) ve $35.8^{\circ}, 43.7^{\circ}, 58.3^{\circ}, 69.5^{\circ}, 51.6^{\circ}, 53.4^{\circ}, 62.8^{\circ}, 63.5^{\circ}, 71.1^{\circ}, 75.2^{\circ}$ ve $76.3^{\circ}$ deki pikler ise $\mathrm{Al}_{2} \mathrm{O}_{3}{ }^{\circ} \mathrm{e}$ (JCPDS pdf \#:85-1337) atfedilebilir. Kristalinite boyutunu hesaplamak için Scherrer denklemi kullanılmış̧ır, $\mathrm{S}=K \lambda / \beta \cos \theta$ denkleminde $K$ :Scherrer sabiti $(0.94), \lambda$ : X-1şını dalga boyu $(0.15406 \mathrm{~nm})$ ve $\beta: 2 \theta^{\prime}$ da yarı yükseklikteki pik genişliğidir [20,21]. Scherrer denklemi ile asit ortamında oluşan $\mathrm{Al}_{2} \mathrm{O}_{3}$ 'e ait kristalinite değerleri $\mathrm{H}_{3} \mathrm{BO}_{3}$ için $46.28 \mathrm{~nm}$, TA için $46.19 \mathrm{~nm}$ ve $\mathrm{H}_{2} \mathrm{C}_{2} \mathrm{O}_{4}$ için $43.98 \mathrm{~nm}$ olarak hesaplanmıştır. Sonuç olarak, kullanılan asit türüne bağlı olmaksızın AA5754 yüzeyinde kristalin $\mathrm{Al}_{2} \mathrm{O}_{3}$ oluştuğu söylenebilir. 


\begin{tabular}{|c|c|c|}
\hline & $\begin{array}{l}\text { BŞEÜ Fen Bilimleri Dergisi } \\
8(2), 978-989,2021\end{array}$ & $\begin{array}{r}\text { BSEU Journal of Science } \\
\text { https://doi.org/10.35193/bseufbd.980581 }\end{array}$ \\
\hline $\begin{array}{l}\text { BiLECIKSEYYH EDEBALI } \\
\text { UNIVERSITESI }\end{array}$ & & 2458-7575 (https://dergipark.org.tr/tr/pub/bseufbd) \\
\hline
\end{tabular}

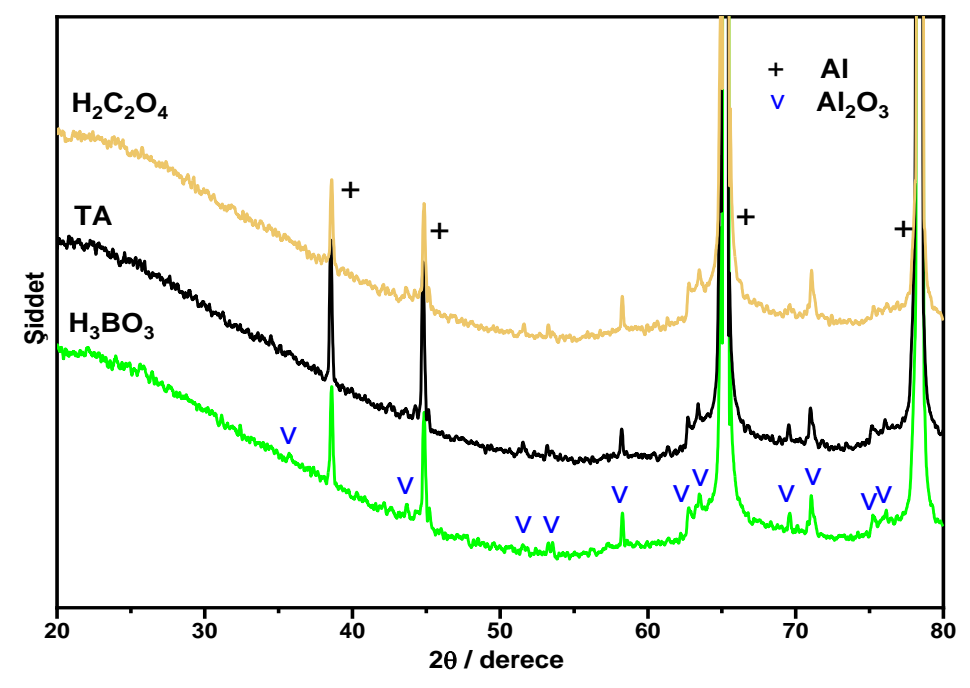

Şekil 1. 0.1 Masit çözeltilerine maruz kalmış AA5754 numunesinin XRD spektrumları

2) XPS: $0.1 \mathrm{M} \mathrm{H}_{3} \mathrm{BO}_{3}, \mathrm{TA}, \mathrm{H}_{2} \mathrm{C}_{2} \mathrm{O}_{4}, \mathrm{HCl}, \mathrm{HF}$ ve $\mathrm{HBF}_{4}$ çözeltilerine maruz kalmış AA5754 numunesinin ara yüzey özelliklerini belirlemek için XPS analizi gerçekleştirilmiştir (Şekil 2). XPS genel taramalarında $\mathrm{H}_{3} \mathrm{BO}_{3}$ için $\mathrm{B}, \mathrm{Al}$ ve $\mathrm{O}$; $\mathrm{TA}$ ve $\mathrm{H}_{2} \mathrm{C}_{2} \mathrm{O}_{4}$ için $\mathrm{C}$, $\mathrm{Al}$ ve $\mathrm{O}$; $\mathrm{HCl}$ için $\mathrm{Cl}$, $\mathrm{Al}$ ve $\mathrm{O}$; $\mathrm{HF}$ için $\mathrm{F}, \mathrm{Al}$ ve $\mathrm{O}$; ve $\mathrm{HBF}_{4}$ için $\mathrm{B}, \mathrm{F}, \mathrm{Al}$ ve $\mathrm{O}$ piklerinin gözlenmesi, yüzeyde $\mathrm{Al}_{2} \mathrm{O}_{3}$ oluşumuna ve çalışılan asitlerin yüzeye adsorpsiyonuna atfedilebilir (Şekil 2(A)). Ayrıntılı incelenme için asitler ile muamele edilmiş yüzeylerde O1s, Al2p ve C1s bantlarının XPS kısmi taramaları gerçekleştirilmiştir. Al2p bantları dekonvole edildiğinde (Şekil 2(B)) Al (73.0 eV) pikinin yanında Al-O (74.5 eV) piki tanımlanmış ve $\mathrm{H}_{3} \mathrm{BO}_{3}$ 'den $\mathrm{HBF}_{4}$ 'e gidildikçe $\mathrm{Al}-\mathrm{O}$ pik şiddetinin $\mathrm{Al}$ pik şiddetine oranının azaldığı belirlenmiştir. O1s bantları dekonvole edildiğinde ise $531.5 \mathrm{eV}$ 'dekipik Al-O bağının varlığını desteklemektedir. $\mathrm{Bu}$ bulgular yüzeyde $\mathrm{Al}_{2} \mathrm{O}_{3}$ oluşumuna ve $\mathrm{H}_{3} \mathrm{BO}_{3}$ 'den HF'e gidildikçe oksit film kalınlığının azaldığına işaret eder. $\mathrm{HF}_{\text {ve }} \mathrm{HBF}_{4}$ çözeltileri içinde diğerlerine göre $\mathrm{Al}-\mathrm{O}$ pik şiddetinin $\mathrm{Al}$ pik şiddetine oranın en düşük seviyede olması daha ince oksit filmin oluştuğu anlamına gelmektedir. Bu fenomen, asidin kısmi ayrışmasıyla ilişsilendirilebilir $[9,25]$ :

$$
\mathrm{HBF}_{4}+\mathrm{H}_{2} \mathrm{O} \leftrightarrow \mathrm{BF}_{4}^{-}+\mathrm{H}_{3} \mathrm{O}^{+} \quad \mathrm{BF}_{4}^{-}+\mathrm{H}_{2} \mathrm{O} \leftrightarrow \mathrm{HF}+\mathrm{BF}_{3} \mathrm{OH}^{-}
$$

$\mathrm{HF}$ ortamında alüminyum ile florür kompleksinin oluşumu, hidroksit çökelmesinden daha kararlı olduğu için, sonunda çözünür $\mathrm{AlF}_{6}^{-3}$ oluşur. Sonuç olarak ortamdaki $\mathrm{HF}^{\prime}$ in varlığı, yüzeyde daha ince film oluşumuna neden olur.

$\mathrm{H}_{2} \mathrm{C}_{2} \mathrm{O}_{4}$ ve TA ile ilgili spektrumlarda $\mathrm{C} 1 \mathrm{~s}$ ve $\mathrm{O} 1 \mathrm{~s}$ bantlarının dekonvolasyonunda sirasiyla $\mathrm{C}=\mathrm{O}(289.2$ eV) ile C-C (285.7 eV) ait pikler (Şekil 2(C)) ve C=O'e ait pik (530.6 eV) (Şekil 2(D)) tanımlanmıştır. Bu bulgular TA ve $\mathrm{H}_{2} \mathrm{C}_{2} \mathrm{O}_{4}$ ' in diğer asitler gibi AA5754 numunenin yüzeyine adsorpsiyonunu doğrulamaktadır. 


\begin{tabular}{|c|c|c|}
\hline & $\begin{array}{l}\text { BŞEÜ Fen Bilimleri Dergisi } \\
8(2), 978-989,2021\end{array}$ & $\begin{array}{r}\text { BSEU Journal of Science } \\
\text { https://doi.org/10.35193/bseufbd.980581 }\end{array}$ \\
\hline $\begin{array}{l}\text { - BILECIKSEYH EDEE } \\
\text { ONIVERSITE }\end{array}$ & & 2458-7575 (https://dergipark.org.tr/tr/pub/bseufbd) \\
\hline
\end{tabular}
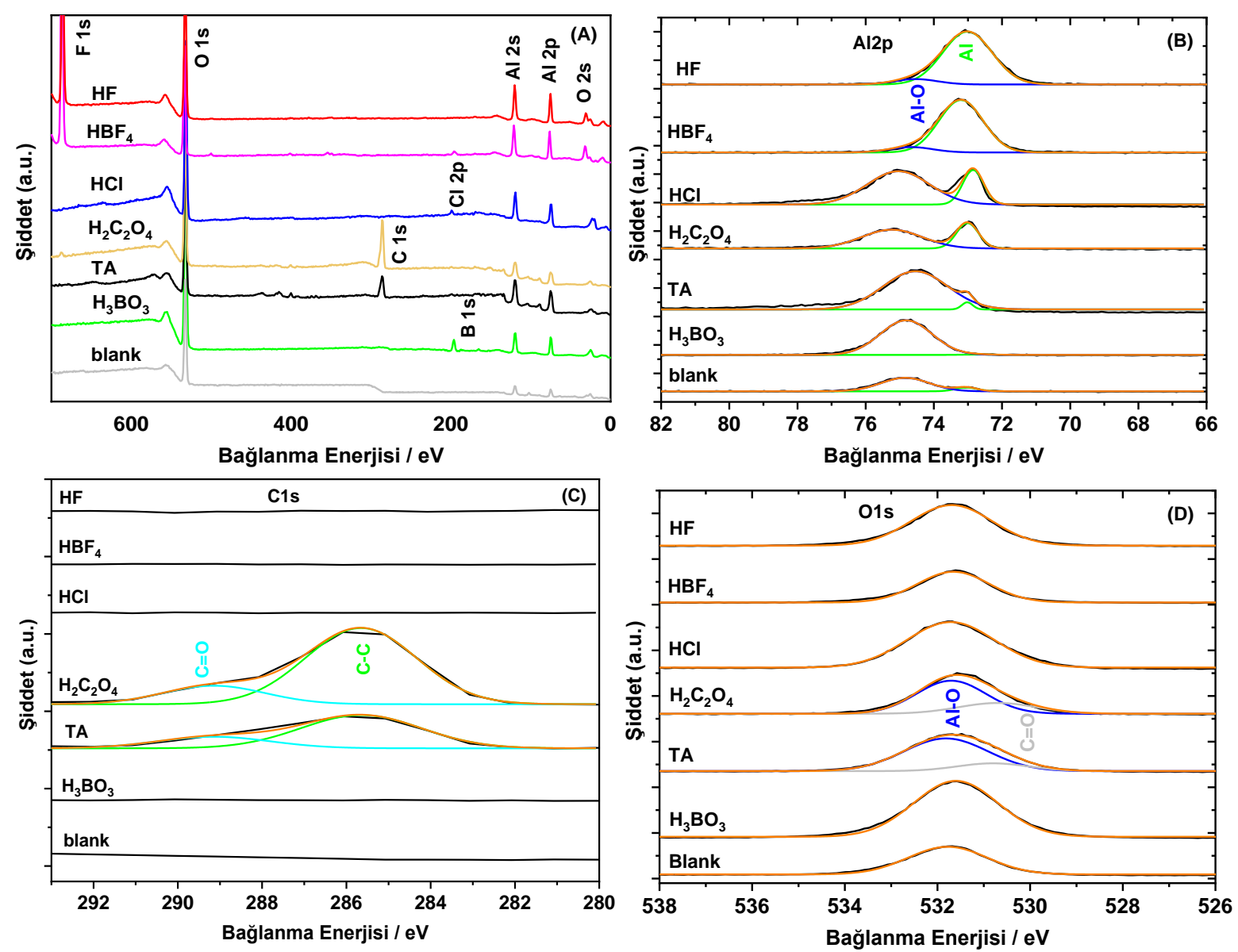

Şekil 2. 0.1 M asit çözeltilerine maruz kalmış AA5754 numunesinin (A) tam tarama, (B) Al2p, (C) C1s ve (D) O1s XPS spektrumları

3) AFM ve Profilometre: Oluşan alüminyum oksit filminin kalınlığı ve yüzey özellikleri malzemenin içinde bulunduğu çözelti ortamına önemli derecede bağlı olduğu bilindiğinden [22], $0.1 \mathrm{MH}_{3} \mathrm{BO}_{3}, \mathrm{TA}_{,} \mathrm{H}_{2} \mathrm{C}_{2} \mathrm{O}_{4}$, $\mathrm{HCl}, \mathrm{HF}$ ve $\mathrm{HBF}_{4}$ çözeltileri ile muamele edilen AA5754 numunesinin yüzey topografyası ve morfolojisi profilometre ile incelenmiştir. Yüzey tabakasının pürüzlülük ve kalınlık değerleri ise 3D-AFM ile belirlenmiş ve Tablo 1'de listelenmiştir. Yüzeylerin mikro yap1 görüntüleri Şekil 3'de sunulmuştur. Profilometre görüntüleri incelendiğinde, $\mathrm{HBF}_{4}$ 'den $\mathrm{H}_{3} \mathrm{BO}_{3}$ 'e doğru tepelere ait kavislerin keskinden yumuşaklığa doğru değiştiği ve ayrıca tepe ve çukurlar birleştiği için homojen bir şekilde numune yüzeyini kapladığı görülmektedir. Literatürdeki çalışmalara benzer şekilde tepe ve çukurların sıklaşması porozitenin azalmasına, daha yoğun oksit tabakası oluşmasına ve nihayetinde korozyon korumasının artmasına neden olmaktadır [5,21,23-25]. Sonuç olarak $\mathrm{H}_{3} \mathrm{BO}_{3}$, TA ve $\mathrm{H}_{2} \mathrm{C}_{2} \mathrm{O}_{4}$ ortamlarında elde edilen oksit tabakaları $\mathrm{HCl}$, $\mathrm{HF}$ ve $\mathrm{HBF}_{4}$ 'dekilere göre daha düşük pürüzlülük değerine ve daha düzgün topografyaya sahiptir. $\mathrm{HCl}, \mathrm{HF}$ ve $\mathrm{HBF}_{4}$ çözeltilerine maruz kalan yüzeylerde derin gözeneklerin oluştuğu düzensiz bir topografya gözlenmektedir. Tüm asitler karşılaştırıldığında $\mathrm{H}_{3} \mathrm{BO}_{3}$ ortamında en kalın (15.4 nm), en düşük pürüzlülük değerlerine $(24.28 \mathrm{~nm})$ sahip ve dolayısıyla en yoğun oksit filmin oluştuğu ortaya çıkmaktadır (Tablo 1). 


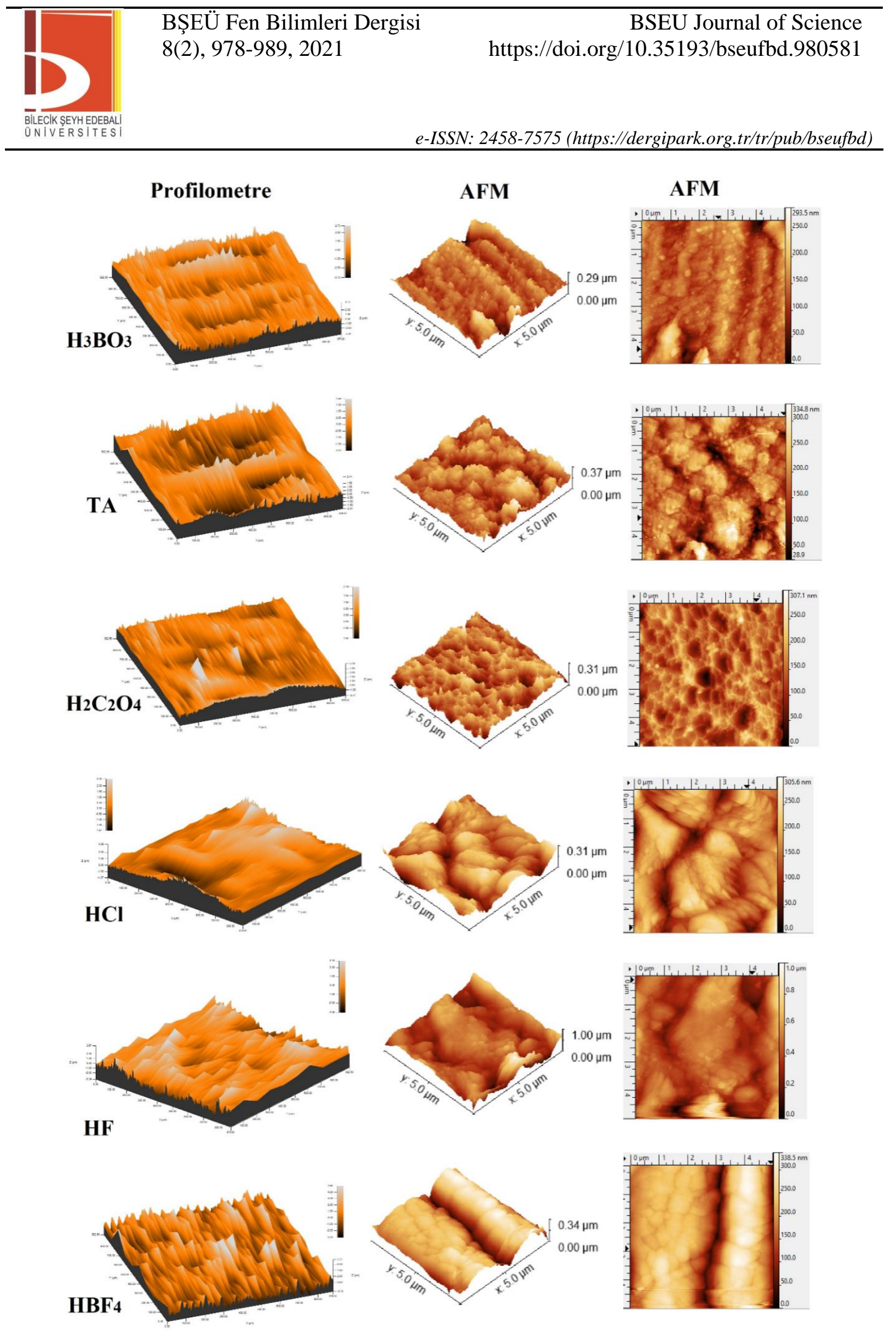

Şekil 3. 0.1 Masit çözeltilerine maruz kalmış AA5754 numunesinin profilometre haritalaması $(900 \mu \mathrm{m}$ x $900 \mu \mathrm{m})$ ve AFM topografya görüntüsü ile $3 \mathrm{D}$ haritalaması $(5 \mu \mathrm{m} \times 5 \mu \mathrm{m})$. 
Tablo 1. $0.1 \mathrm{M}$ asit çözeltilerine maruz kalmış AA5754 numunesi için AFM topografya görüntülerinden elde edilen kalınlık ve pürüzlülük değerleri.

\begin{tabular}{ccc}
\hline Asit ortamı & Kalınlık /nm & Pürüzlülük /nm \\
\hline $\mathrm{H}_{3} \mathrm{BO}_{3}$ & 15.4 & $24.28 \pm 7.23$ \\
$\mathrm{TA}$ & 8.01 & $30.25 \pm 5.55$ \\
$\mathrm{H}_{2} \mathrm{C}_{2} \mathrm{O}_{4}$ & 4.28 & $35.02 \pm 7.76$ \\
$\mathrm{HCl}$ & 3.29 & $38.15 \pm 9.15$ \\
$\mathrm{HF}$ & 0.69 & $50.44 \pm 5.42$ \\
$\mathrm{HBF}_{4}$ & 0.64 & $99.44 \pm 36.9$ \\
\hline
\end{tabular}

\section{B. Çeşitli Asitlerin Bulunduğu Ortamda AA5754 Numunesinin Korozyon Davranışı}

1) OCP: $0.1 \mathrm{M} \mathrm{H}_{3} \mathrm{BO}_{3}, \mathrm{TA}, \mathrm{H}_{2} \mathrm{C}_{2} \mathrm{O}_{4}, \mathrm{HCl}, \mathrm{HF}$ ve $\mathrm{HBF}_{4}$ çözeltilerine daldırılmış AA5754 numunesinin açık devre potansiyel (OCP) ölçümü altı saat süreyle gerçekleştirilmiştir (Şekil 4). Numunenin $\mathrm{H}_{2} \mathrm{C}_{2} \mathrm{O}_{4}$ ve $\mathrm{HCl}$ çözeltilerine daldırılmasıyla başlangıç OCP değerlerindeki keskin artış çekirdeklenmeye, ardından gözlenen azalma ise pasifleşmeye atfedilebilir $[4,13,14] . \mathrm{H}_{3} \mathrm{BO}_{3}$ ve TA ortamlarında ise çekirdeklenmeden sonra OCP değeri zamanla çok yavaş bir şekilde azalmaktadır. Bunun nedeni, çekirdeklenme ile birlikte tüm yüzeyde hızlı bir şekilde pasivasyonun meydana gelmesi ve sonuçta daha pürüzsüz, kalın bir tabakanın (Tablo 1) oluşmasından kaynaklanabilir. $\mathrm{HF}$ ve $\mathrm{HBF}_{4}$ durumunda ise $\mathrm{OCP}$ eğrileri hem daha negatif potansiyellerde hem de kararsiz olmasi yönüyle diğerlerine göre çok farklılık göstermektedir. Bunun nedeni HF/su ortamında çözünmenin daha fazla gerçekleşmesi olmalıdır (R1). Ayrıca $\mathrm{HBF}_{4}$ ortamında HF'e göre çok daha negatif OCP değerlerinin kaydedilmesi, $\mathrm{HBF}_{4}{ }^{\prime} \mathrm{ün}\left(\mathrm{pK}_{\mathrm{a}}=0.50\right)$ [26], $\mathrm{HF}^{\prime} \mathrm{e}\left(\mathrm{pK}_{\mathrm{a}}=3.20\right)$ [26] göre daha asidik ortam sağlamasına bağlanabilir. Eğrilerin tümü karşılaştırıldığında kararlı hale geldikten sonra OCP değerlerinin $\mathrm{H}_{3} \mathrm{BO}_{3}, \mathrm{TA}, \mathrm{H}_{2} \mathrm{C}_{2} \mathrm{O}_{4}, \mathrm{HCl}$, $\mathrm{HF}$ ve $\mathrm{HBF}_{4}$ 'e sıralamasıyla daha negatif değerlere kaydığı görülmektedir. Sonuçta $\mathrm{H}_{3} \mathrm{BO}_{3}$, TA ve $\mathrm{H}_{2} \mathrm{C}_{2} \mathrm{O}_{4}$ benzer OCP değerleri göstermekle birlikte en pozitif değere $\mathrm{H}_{3} \mathrm{BO}_{3}$ çözeltisi içerisinde ulaşılmaktadır. Buna göre, $\mathrm{H}_{3} \mathrm{BO}_{3}$ içinde oluşan oksit tabakasının en etkin bariyer özelliği sergilediği sonucuna varılabilir.

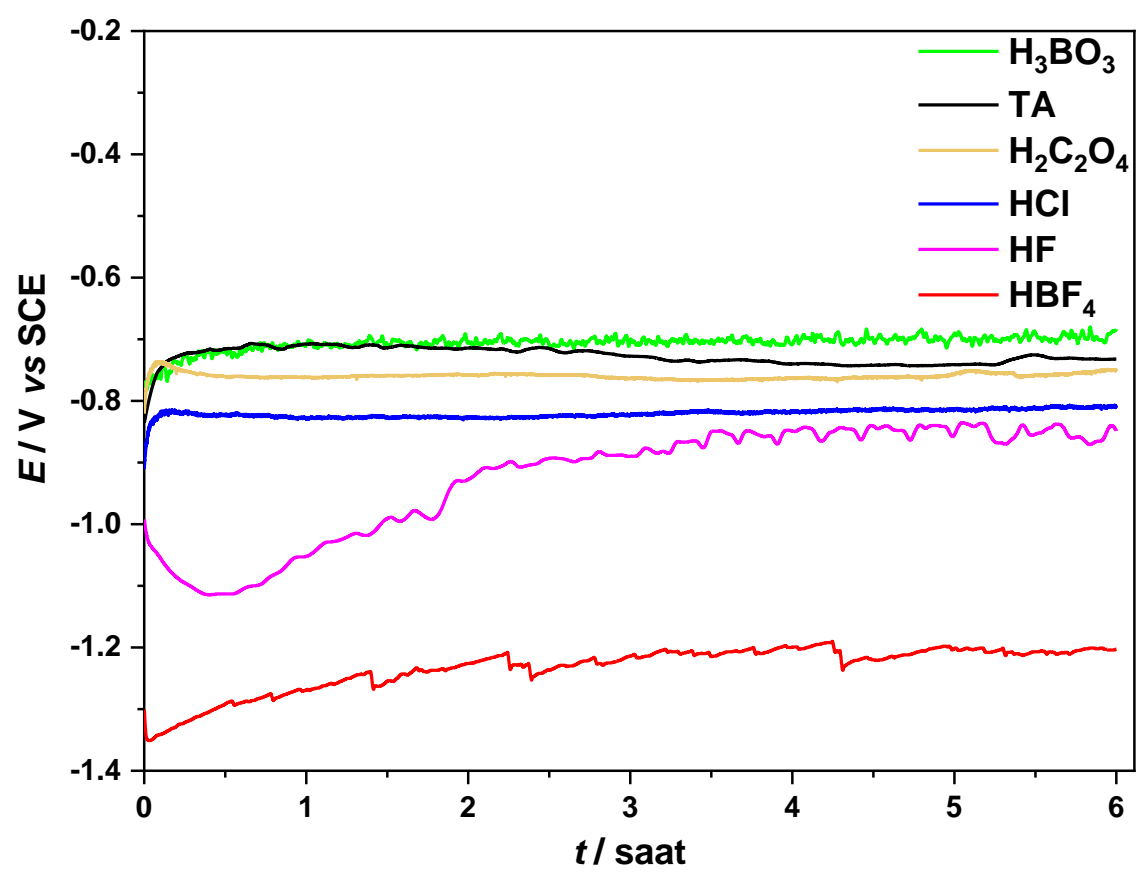

Şekil 4. 0.1 M asit çözeltilerine daldırılmış AA5754 numunesinin zamana karşı OCP ölçümleri.

2) Tafel: Tafel testi güvenilir olması ve hızlı sonuç vermesi nedeni ile kinetik parametreleri değerlendirmek için korozyon çalışmalarında yaygın olarak kullanılmaktadır[21,27,28]. Uygulanan potansiyele (E) karşı cevap olarak alınan akım yoğunluğu $(i)$ değerleri logaritmasının grafiğe geçirilmesi ile elde edilen Tafel 
eğrisi hem anodikhem de katodik dallar içerir. Anodik ve katodik dalların kesişimi korozyon potansiyelini ve akımını gösterir [29]. AA5754'ün korozyon dayanımın çalışılan asit ortamına bağımlılığı Tafel analizi ile incelenmiştir. Tafel eğrilerinde hem anodik hem de katodik dallar birbiriyle karşılaştırılırsa en yüksek akım yoğunluğu $\mathrm{HBF}_{4}$ 'e ait eğride ve en düşük akım yoğunluğu $\mathrm{H}_{3} \mathrm{BO}_{3}$ 'e ait eğride gözlenmektedir (Şekil 5). Derişik çözeltilerde Tafel bölgesi net olarak belirlenemediği için korozyon akımı ve potansiyeli ( $E_{\text {kor }}$ ve $\left.i_{\text {kor }}\right)$ doğru bir şekilde belirlenememektedir [30,31]. Fakat, elde edilen eğrilerin birbirinden çok farklı potansiyel aralıklarında olması karşılaştırmanın kabaca yapılabilmesine olanak sağlamaktadır. Yaklaşık olarak belirlenen $E_{\text {kor }}$ değerinden $0.1 \mathrm{~V}$ daha potitif potansiyeldeki akım değerleri veya yaklaşı olarak belirlenen $i_{\text {kor }}$ değerleri en düşükten (yaklaşık olarak sırasıyla $i_{0.1 \mathrm{v}}=-5.17 \mu \mathrm{A} \mathrm{cm} \mathrm{c}^{-2} \mathrm{veya} i_{\mathrm{kor}}=-5.97 \mu \mathrm{A} \mathrm{cm} \mathrm{cm}^{-2}$ ) en yükseğe (yaklaşık olarak sırasıyla $i_{0.1 \mathrm{v}}=-4.42 \mu \mathrm{A} \mathrm{cm}$ ${ }^{2}$ veya $\left.i_{\text {kor }}=-4.61 \mu \mathrm{A} \mathrm{cm}{ }^{-2}\right) \mathrm{H}_{3} \mathrm{BO}_{3}, \mathrm{TA}, \mathrm{H}_{2} \mathrm{C}_{2} \mathrm{O}_{4}, \mathrm{HCl}$, HF ve $\mathrm{HBF}_{4}$ siralamasıyla artmaktadır. Dolayısıyla en çok çözünme $\mathrm{HF}$ ve $\mathrm{HBF}_{4}$ ortamlarında gerçekleşmektedir. $\mathrm{H}_{3} \mathrm{BO}_{3}, \mathrm{TA}, \mathrm{H}_{2} \mathrm{C}_{2} \mathrm{O}_{4}$ ve $\mathrm{HCl}$ için pK $\mathrm{a}$ değerleri de sırasıyla 9.27; 3.03; 1.27 ve -6.3 olarak azalmaktadır [26]. Buradan asidin kuvveti arttıkça alüminyum oksit tabakasının kalınlığının azaldığı (Tablo 1) sonucuna varılabilir. $\mathrm{HF}\left(\mathrm{pK}_{\mathrm{a}}=3.20\right)$ ve $\mathrm{HBF}_{4}\left(\mathrm{pK}_{\mathrm{a}}=0.50\right)$ durumunda ise asitlerin kuvvetine ek olarak $\mathrm{AlF}_{6}^{-3}$ kompleksinin oluşumu (R1), çözünmeyi diğerlerine göre daha fazla arttırdığını göstermektedir.

$E_{\text {kor }}$ değerleri ise $i_{\text {kor }}$ ile aynı sıralamayla daha negatif potansiyellere doğru $\left(\mathrm{H}_{3} \mathrm{BO}_{3}\right.$ : yaklaşık-0.39 V'den $\mathrm{HBF}_{4}$ : yaklaşık-1.10 V’ye) kaymaktadır. Daha pozitif potansiyel daha kalın ve daha kararlı tabaka oluştuğuna

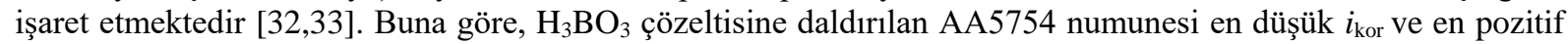

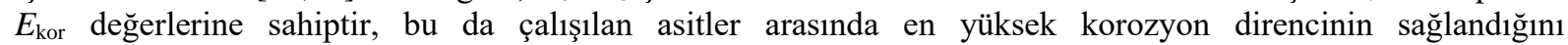
göstermektedir. $\mathrm{Bu}$ sonuç $\mathrm{H}_{3} \mathrm{BO}_{3}$ çözeltisinde oluşan oksit filminin en kalın ve en az pürüzlülüğe sahip olması (Tablo 1) ile uyumludur. Sonuç olarak, OCP verilerine paralel olarak $\mathrm{HBF}_{4}, \mathrm{HF}, \mathrm{HCl}, \mathrm{H}_{2} \mathrm{C}_{2} \mathrm{O}_{4}, \mathrm{TA}_{\text {ve }} \mathrm{H}_{3} \mathrm{BO}_{3}$, sıralamasıyla korozyon performansı giderek artmakta ve en yüksek dirence sahip en kararlı oksit film kaplı yüzey $\mathrm{H}_{3} \mathrm{BO}_{3}$ ortamında elde edilmektedir.

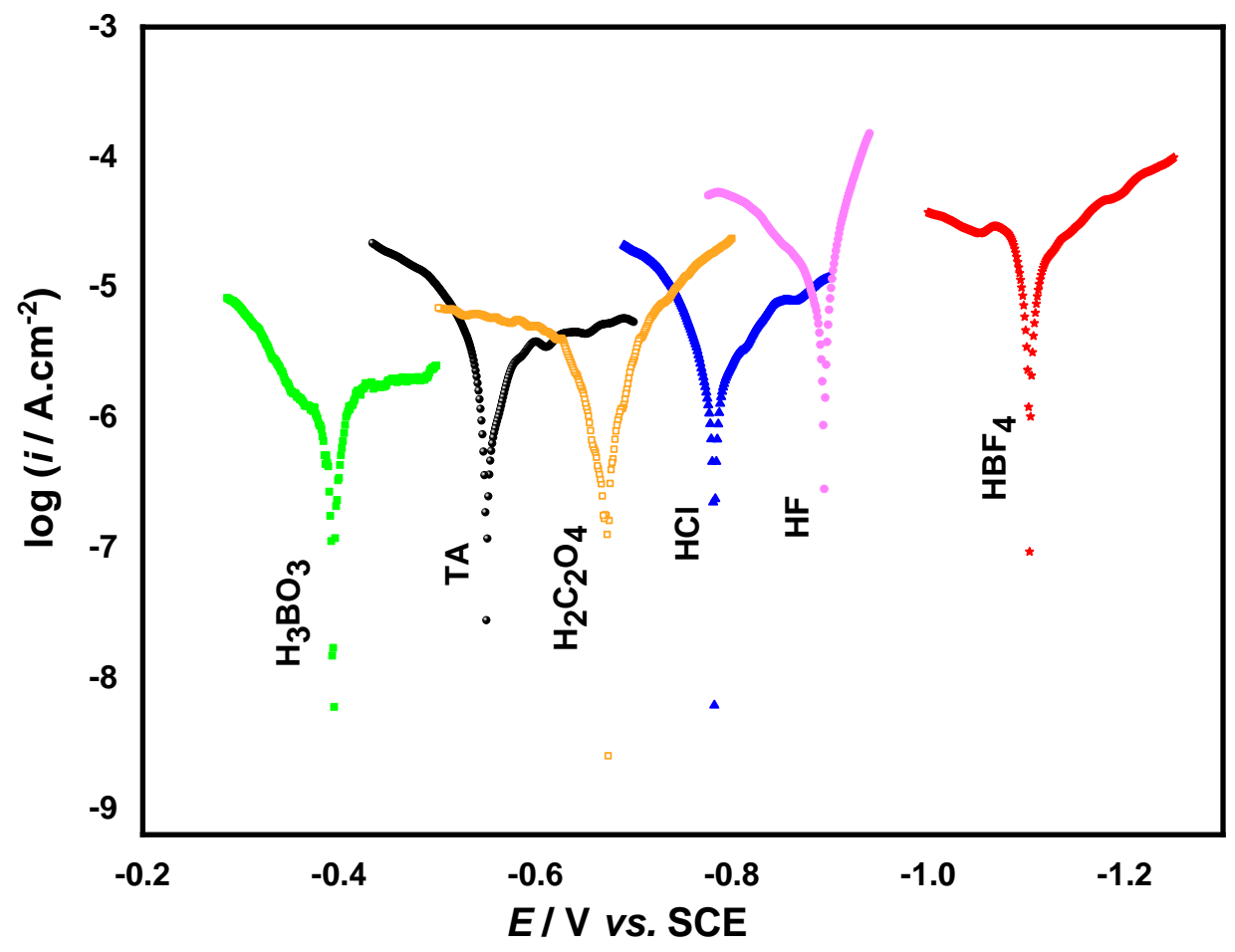

Şekil 5. 0.1 M asit çözeltilerine daldırılmış AA5754 numunesine ait Tafel eğrileri, $v=1 \mathrm{mV} \mathrm{s}^{-1}$.

3) EIS: Elektrokimyasal empedans spektroskopi (EIS) yöntemi ile AA5754 yüzey özelliklerinin ortama bağımlılığ incelenmiş ve her bir asit ortamında korozyona karşı dirençleri karşılaştırılmıştır. $0.1 \mathrm{M} \mathrm{H}_{3} \mathrm{BO}_{3}$, TA, $\mathrm{H}_{2} \mathrm{C}_{2} \mathrm{O}_{4}, \mathrm{HCl}, \mathrm{HF}$ ve $\mathrm{HBF}_{4}$ çözeltilerine daldırılmış AA5754 numunesine ait OCP değerleri durağan hale ulaştıktan sonra (yaklaşık 10 dakika) Nyquist ve Bode eğrileri kaydedilmiştir(Şekil 6). Nyquist diyagramı korozyon süreci ile ilişkili bir basık yarım daire şeklinde olup çapı $\mathrm{HBF}_{4}, \mathrm{HF}, \mathrm{HCl}, \mathrm{H}_{2} \mathrm{C}_{2} \mathrm{O}_{4}$, TA ve $\mathrm{H}_{3} \mathrm{BO}_{3}$ siralamasıyla 
artmaktadır. ZSimpWin V3.50 yazılımı ile deneysel verilere en uyumlu eşdeğer devrenin $\mathrm{R}_{\mathrm{s}}\left(\mathrm{QR}_{\mathrm{ct}}\right)$ olduğu belirlenmiştir. Nyquist grafiğine ait çakışma eğrileri Şekil 6 içinde çizgi ile sunulmuştur. Önerilen eşdeğer devre modelinde $R_{\mathrm{s}}$ çözelti direnci, $R_{\mathrm{ct}}$ yük transfer direnci ve $Q$ sabit faz elemanıdır. Çakıştırma sonucunda elde edilen empedans parametreleri ile $\chi^{2}$ değerleri Tablo 2'de sunulmuştur. $Q$ ile ters orantılı olan $R_{\mathrm{ct}}$ değerleri $\mathrm{HBF}_{4}, \mathrm{HF}_{\text {, }}$ $\mathrm{HCl}, \mathrm{H}_{2} \mathrm{C}_{2} \mathrm{O}_{4}$, TA ve $\mathrm{H}_{3} \mathrm{BO}_{3}$ siralamasiyla giderek artmaktadır. Bode diyagramlarından elde edilen maksimum faz açısı aynı sıralamayla artarken maksimum faz açılarındaki $\log ($ frekans)'da daha düşük değerlere kaymaktadır (Tablo 2). Bu bulgular kaplamanın koruyucu özelliğinin $\mathrm{HBF}_{4}, \mathrm{HF}, \mathrm{HCl}, \mathrm{H}_{2} \mathrm{C}_{2} \mathrm{O}_{4}, \mathrm{TA}$ ve $\mathrm{H}_{3} \mathrm{BO}_{3}$ siralamasıyla giderek artığını göstermektedir. Oluşan oksit tabakalarının yüksek korozyon direnci sağlamasının nedeni, $\mathrm{H}_{3} \mathrm{BO}_{3}$ 'in diğerlerine göre zayıf asidik karakterde olması, TA ortamında $\mathrm{Al}_{2} \mathrm{O}_{3}$ 'ün yüksek kristalinitede oluşturulabilmesi [13] ve $\mathrm{H}_{2} \mathrm{C}_{2} \mathrm{O}_{4}$ ortamında $\mathrm{Al}_{2} \mathrm{O}_{3}$ 'ün daha düşük porozitede biriktirilebilmesi [16] olabilir. Sonuç olarak OCP ve Tafel deneylerine paralel olarak elektrot ve elektrolit ara yüzeyinde korozyona karşı en etkili yüzey $\mathrm{H}_{3} \mathrm{BO}_{3}$ varlığında elde edilirken $\mathrm{HBF}_{4}$ ortamında $\mathrm{AlF}_{6}{ }^{-3}$ kompleks oluşumunun da (R1) katkısıyla tam tersidir.

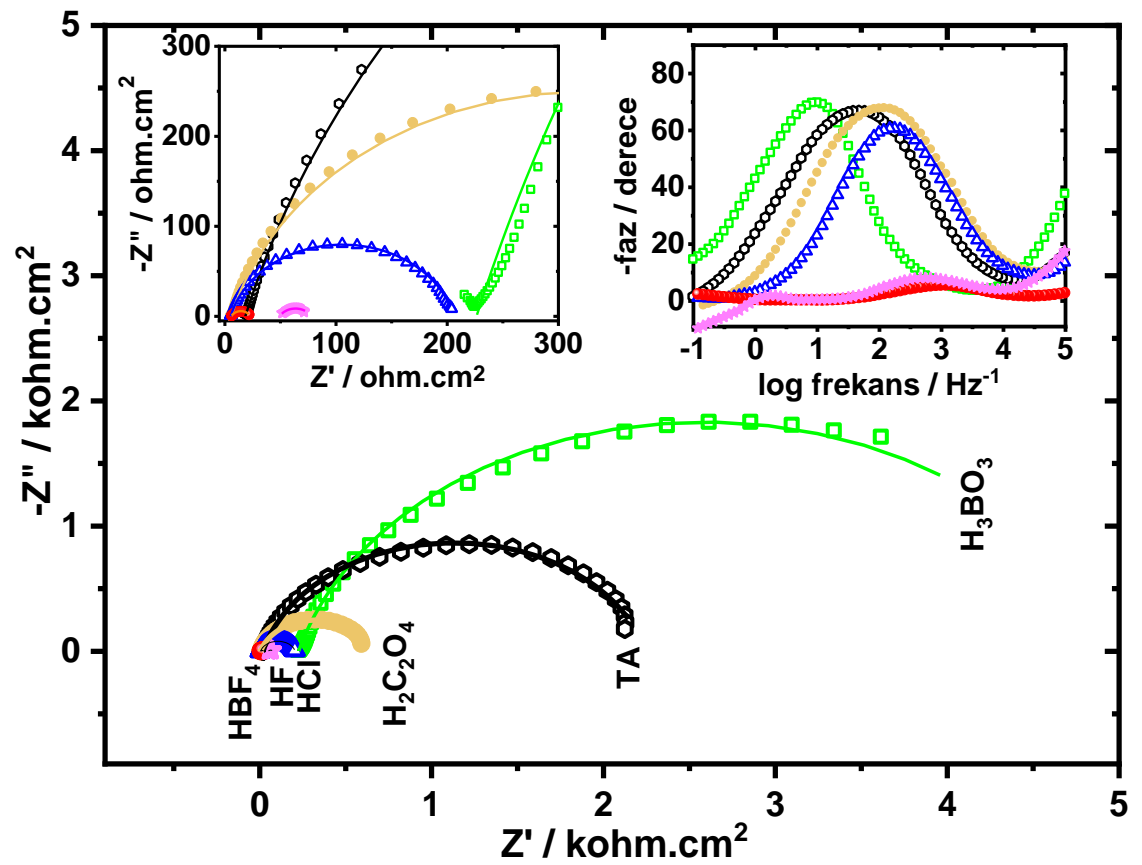

Şekil 6. $0.1 \mathrm{M}$ asit çözeltilerine daldırılmış AA5754 numunesinin Nyquist eğrileri (İçeride: Bode ve büyütülmüş Nyquist eğrileri).

Tablo 2. 0.1 M asit çözeltilerine daldırılmış AA5754 numunesinin Şekil 6'daki eğrilerinden elde edilen empedans parametreleri.

\begin{tabular}{|c|c|c|c|c|c|c|}
\hline $\begin{array}{c}\text { Asit } \\
\text { ortamı }\end{array}$ & $\begin{array}{c}\text { Maksimum } \\
\text { Faz Açısı / }\end{array}$ & $\begin{array}{c}\log (\text { frekans }) / \\
\mathbf{H z}^{-1}\end{array}$ & $\begin{array}{c}R_{\mathrm{S}} / \\
\Omega \mathrm{cm}^{2}\end{array}$ & $\begin{array}{c}C P E_{\mathrm{c}} / \\
\mu \mathrm{F}^{\mathrm{n} 1} \mathrm{~cm}^{-2}\end{array}$ & $\begin{array}{c}R_{\mathrm{ct}} / \\
\Omega \mathrm{cm}^{2}\end{array}$ & $\chi^{2}$ \\
\hline $\mathrm{H}_{3} \mathrm{BO}_{3}$ & 71.0 & 0.97 & 226 & 2.67 & 4719 & 0.00192 \\
\hline TA & 67.7 & 1.66 & 18.4 & 3.24 & 2225 & 0.00513 \\
\hline $\mathrm{H}_{2} \mathrm{C}_{2} \mathrm{O}_{4}$ & 68.5 & 2.08 & 5.72 & 4.75 & 640.1 & 0.00420 \\
\hline $\mathrm{HCl}$ & 61.6 & 2.24 & 5.31 & 5.46 & 200.6 & 0.00351 \\
\hline HF & 8.79 & 2.74 & 49.4 & 9.58 & 28.3 & 0.00007 \\
\hline $\mathrm{HBF}_{4}$ & 5.83 & 3.18 & 58.8 & 9.58 & 17.0 & 0.00056 \\
\hline
\end{tabular}

4) Literatür Sonuçları ile Karşılaştırma: Aluminyum endüstrisinde anodizasyon proseslerinde özellikle $\mathrm{H}_{3} \mathrm{BO}_{3}$ [5,11], TA [6,10,13,14] ve $\mathrm{H}_{2} \mathrm{C}_{2} \mathrm{O}_{4}$ [16] yaygın olarak tercih edilmektedir. Alümünyum alaşımın anodizasyonunda fosforik asit-borik asit ortamında $22.52 \mathrm{k} \Omega \mathrm{cm}^{2}$ [8], fosforik asit ortamında $16.41 \mathrm{k} \Omega \mathrm{cm}^{2}$ [8], sülfürik asit-borik asit-fosforik asit karışımında $6500 \mathrm{k} \Omega \mathrm{cm}^{2}$ [9], borik asit-sülfürik asit ortamında $2.122 \mathrm{k} \Omega \mathrm{cm}^{2}$ [5,7,11],sülfürik asit ortamında $2850.1 \mathrm{k} \Omega \mathrm{cm}^{2}$ [12], sülfürik asit-adipik asit karışımında $2953.8 \mathrm{k} \Omega \mathrm{cm}^{2}$ [12],borik asitte $9274 \mathrm{k} \Omega \mathrm{cm}^{2}$ [6], borik asit-tartarik asit karışımında $6829 \mathrm{k} \Omega \mathrm{cm}^{2}$ [6] ve sülfürik asit-tartarik asit karışımında $170 \mathrm{k} \Omega \mathrm{cm}^{2}$ elde edilmiştir. Sitrik asit-fosforik asit buharının oksit tabakasının kalınlığını $1 \mu \mathrm{m}$ arttırdı ğ gözlenmiştir [4]. Literatürden farklı olarak alüminyum alaşımlarının bulunduğu ortamlarda elektrolit olarak 
kullanılabilme potansiyeli olan asit çözeltilerinde oluşan oksit tabakasının özellikleri ve korozyon davranışları araştırılmıştır. Bu çalışmada en yüksek sonucun elde edildiği borik asit ortamındaki direnç değeri $4.719 \mathrm{k} \Omega \mathrm{cm}^{2}$ değeri, daldırma ile elde edilmesine rağmen literatürle yarışabilecek düzeydedir.

\section{SONUÇLAR}

Elektrolit olarak çeşitli uygulamalarda kullanılabilecek olan $\mathrm{H}_{3} \mathrm{BO}_{3}, \mathrm{TA}, \mathrm{H}_{2} \mathrm{C}_{2} \mathrm{O}_{4}, \mathrm{HCl}$, $\mathrm{HF}$ ve $\mathrm{HBF}_{4}$ ‘ün $0.1 \mathrm{M}$ çözeltilerinde AA5754 numunesi bekletilmiş ve elde edilen yüzeyler XRD, XPS, AFM ve profilometre yöntemleri ile karakterize edilerek bu ortamda korozyon performansları karşılaştııılmıştır. XRD ve XPS sonuçları yüzeyde kristalin $\mathrm{Al}_{2} \mathrm{O}_{3}$ oluşumunu ve çalış̧lan asitlerin yüzeye adsorpsiyonunu göstermiştir. $\mathrm{H}_{3} \mathrm{BO}_{3}$, TA ve $\mathrm{H}_{2} \mathrm{C}_{2} \mathrm{O}_{4}$ ortamlarında elde edilen oksit tabakalarının $\mathrm{HCl}$, $\mathrm{HF}$ ve $\mathrm{HBF}_{4}$ 'dekilere göre daha düşük pürüzlülük değerine ve daha düzgün topografyaya sahip oldukları belirlenmiştir. Korozyon davranışları incelendiğinde yüzeyde büyüyen oksit tabakasının koruyucu özelliğinin $\mathrm{HBF}_{4}, \mathrm{HF}, \mathrm{HCl}, \mathrm{H}_{2} \mathrm{C}_{2} \mathrm{O}_{4}$, TA ve $\mathrm{H}_{3} \mathrm{BO}_{3}$ siralamasıyla giderek arttığı belirlenmiştir. $\mathrm{HBF}_{4}$ 'ün sulu ortamında kısmi ayrışma sonucu üretilen $\mathrm{HF}$ sayesinde yüzeyde $\mathrm{AlF}_{6}{ }^{-}$ ${ }^{3}$ kompleksinin oluşumu ile çözünmenin daha fazla gerçekleşmesi, $\mathrm{HF}$ ve $\mathrm{HBF}_{4}$ sulu ortamlarında AA5754 numunesinin korozyon dayanımını azalttığı görülmüsştür. Neticede, $\mathrm{H}_{3} \mathrm{BO}_{3}$ 'te oluşan oksit tabakasının hem en kalın hem de korozif türlere karşı en iyi bariyer özelliğe sahip olduğu ortaya çıkmıştır. Bunun nedeni, $\mathrm{H}_{3} \mathrm{BO}_{3}$ diğerlerine göre zayıf asidik karakterde $\left(\mathrm{pK}_{\mathrm{a}}=9.27\right)$ olması sayesinde çekirdeklenme ile birlikte çok hızlı bir şekilde pasivasyonun gerçekleşmesine bağlanmıştır. $\mathrm{H}_{3} \mathrm{BO}_{3}$ çözeltisinde elde edilen direnç değeri $\left(R_{\mathrm{ct}}\right.$ değeri 4719 ohm cm$\left.{ }^{2}\right)$ ile karşılaştırıldığında TA ve $\mathrm{H}_{2} \mathrm{C}_{2} \mathrm{O}_{4}$ çözeltilerinin de koruyucu oksit filmler elde etmek $\left(R_{\mathrm{ct}}\right.$ değerleri

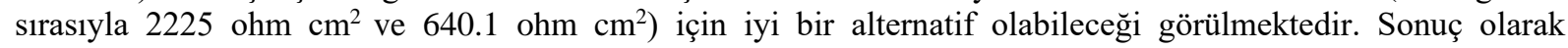
alüminyum alaşımlarının kullanıldığı sulu çözeltilerde elektrolit olarak veya çözeltilere katkı maddesi olarak HF ve $\mathrm{HBF}_{4}$ 'inkullanılmaması gerekliliği ortaya çıkmaktadır, buna karşılık $\mathrm{H}_{3} \mathrm{BO}_{3}$, TA ve $\mathrm{H}_{2} \mathrm{C}_{2} \mathrm{O}_{4}$ kullanılabilme potansiyeli bulunan asitler olduğu belirlenmiştir.

\section{KAYNAKLAR}

[1] Nik, W. M. N. W., \& Olanrewaju, O. S., \& Zulkifli, F. \& Ahmad, M.Rosliza, R. (2014). Corrosion of Aluminium Alloy in Seawater and Development of Green Corrosion Inhibitor for Marine Applications. Marine Technology and Sustainable Development: Green Innovations, 146-156.

[2] Xhanari, K., \& Finšgar, M. (2016). Organic corrosion inhibitors for aluminium and its alloys in acid solutions: a review. $R S C$ advances, 6(67) 62833-62857.

[3] Li, S. Y., \& Church, B. C. (2017). Electrochemical stability of aluminum current collector in aqueous rechargeable lithium-ion battery electrolytes. Journal of Applied Electrochemistry, 47(7) 839-853.

[4] Ud Din, R., Jellesen, M. S., \& Ambat, R. (2015). Role of acidic chemistries in steam treatment of aluminium alloys. Corrosion Science, 99 258-271.

[5] Du, N., \& Wang, S. X., Zhao, Q., \& Shao, Z. S. (2012). Effects of boric acid on microstructure and corrosion resistance of boric/sulfuric acid anodic film on 7050 aluminum alloy. Transactions of Nonferrous Metals Society of China, 22(7), 1655-1660.

[6] Ban, C. L., He, Y. D. \& Shao, X. (2013). Effect of trace tartaric acid on anodizing of etched aluminum foil for high voltage electrolytic capacitor. Journal of Materials Science-Materials in Electronics, 24(9), 34423447.

[7] Cadwell, S. L., \& Lindsey, D. (2003) Accelerated sulfuric acid and boric sulfuric acid anodize process, in Boeing Co, B. Co, Editor: United States.

[8] Quebbou, Z., Chafi, M., \& Omari, L. E. (2021). Corrosion resistance of 5005 aluminum alloy by anodizing treatment in a mixture of phosphoric and boric acids. Materials Today-Proceedings, 37, 3854-3859.

[9] Saeedikhani, M., Javidi, M., \& Vafakhah, S. (2017). Anodising of 2024-T3 aluminium alloy in electrolyte of sulphuric-boric-phosphoric mixed acid containing cerium salt as corrosion inhibitor. Transactions of Nonferrous Metals Society of China, 27(3), 711-721.

[10] Marzocchi, V., Iglesias-Rubianes, L., Thompson, G. E., \& Bellucci, F. (2007). The influence of tartaric acid additions on the anodizing behaviour of AA2024-T3 alloy in sulphuric acid. Corrosion Reviews, 25(3-4), 461-473.

[11] Mert, B. D., Yazici, B., Tuken, T., Kardas, G., \& Erbil, M. (2011). Anodizing and corrosion behaviour of aluminium. Protection of Metals and Physical Chemistry of Surfaces, 47(1), 102-107.

[12] Li, Y. D., Zhang, Y., Li, S. M., \& Zhao, P. Z. (2016). Influence of adipic acid on anodic film formation and corrosion resistance of 2024 aluminum alloy. Transactions of Nonferrous Metals Society of China, 26(2), $492-500$. 
[13] Surganov, V. F., \& Gorokh, G. G. (1993). Anodic Oxide Cellular Structure Formation on Aluminum Films in Tartaric Acid Electrolyte. Materials Letters, 17(3-4), 121-124.

[14] Ma, Y., Zhou, X., Thompson, G. E., Curioni, M., Hashimoto, T., Skeldon, P., Thomson, P., \& Fowles, M. (2011). Anodic Film Formation on AA 2099-T8 Aluminum Alloy in Tartaric-Sulfuric Acid. Journal of the Electrochemical Society, 158(2), C17-C22.

[15] Choudhary, R. K., Mishra, P., Kain, V., Singh, K., Kumar, S., \& Chakravartty, J. K. (2015). Scratch behavior of aluminum anodized in oxalic acid: Effect of anodizing potential. Surface \& Coatings Technology, 283, 135-147.

[16] Keshavarz, A., Parang, Z., \& Nasseri, A. (2013). The effect of sulfuric acid, oxalic acid, and their combination on the size and regularity of the porous alumina by anodization. Journal of Nanostructure in Chemistry, 3(1).

[17] Madakson, P. B., Malik, I. A., Laminu, S. K., \& Bashir, I. G. (2012). Effect of Anodization on the corrosion behavior of Aluminium Alloy in $\mathrm{HCl}$ acid and $\mathrm{NaOH}$. International Journal of Materials Engineering, 2(4), $38-42$.

[18] Thompson, G. E., \& Wood, G. C. (1978). The effect of alternating voltage on aluminium electrodes in hydrochloric acid. Corrosion Science, 18(8), 721-746.

[19] Yi, H., Gu, B., Yang, P., Gong, L., \& Guo, D. (2013). Influence of boric acid on the performance of chromium-free non-oriented silicon steel coating. Jinshu Rechuli/Heat Treatment of Metals, 38(5), 67-70.

[20] Devikala, S., Kamaraj, P., \& Arthanareeswari, M. (2018). Corrosion resistance behavior of PVA/TiO 2 composite in 3.5\% NaCl. Materials Today: Proceedings, 5(2), 8672-8677.

[21] Liu, X., Zhang, T. C., He, H. Q., Ouyang, L. K., \& Yuan, S. J. (2020). A stearic Acid/CeO2 bilayer coating on AZ31B magnesium alloy with superhydrophobic and self-cleaning properties for corrosion inhibition. Journal of Alloys and Compounds, 834.

[22] Pu, Y., Hu, J., Yao, T., Li, L., Zhao, J., \& Guo, Y. (2021). Influence of anodization parameters on film thickness and volume expansion of thick- and large-sized anodic aluminum oxide film. Journal of Materials Science: Materials in Electronics, 32(10), 13708-13718.

[23] Choudhary, R. K., Sreeshma, K. P., \& Mishra, P. (2017). Effect of Surface Roughness of an Electropolished Aluminum Substrate on the Thickness, Morphology, and Hardness of Aluminum Oxide Coatings Formed During Anodization in Oxalic Acid. Journal of Materials Engineering and Performance, 26(7), 3614-3620.

[24] Domínguez-Crespo, M. A., Torres-Huerta, A. M., Rodil, S. E., Ramírez-Meneses, E., Suárez-Velázquez, G. G., \& Hernández-Pérez, M. A. (2009). Effective corrosion protection of AA6061 aluminum alloy by sputtered Al-Ce coatings. Electrochimica Acta, 55(2), 498-503.

[25] Yue, J. Y., \& Cao, Y. (2015). Corrosion Prevention by Applied Coatings on Aluminum Alloys in Corrosive Environments. International Journal of Electrochemical Science, 10(7), 5222-5237.

[26] Weast, R. C., Astle, M. J., \& Beyer, W. H. (1988). CRC handbook of chemistry and physics. 69.

[27] Bard, A. J., Faulkner, L. R., Leddy, J., \& Zoski, C. G. (1980). Electrochemical methods: fundamentals and applications. 2.

[28] Khan, M. F., Kumar, A. M., Ul-Hamid, A., \& Al-Hems, L. M. (2019). Achieving non-adsorptive anodized film on Al-2024 alloy: Surface and electrochemical corrosion investigation. Surfaces and Interfaces, 15, 7888 .

[29] Schweitzer, P. A. (2010). Fundamentals of Corrosion.

[30] Mert, B. D. (2021). Yumuşak Çeliğin Korozyon Davranışı. 32.

[31] Lu, J. Q., Wei, G. Y., Yu, Y. D., Guo, C. F., \& Jiang, L. (2018). Aluminum alloy AA2024 anodized from the mixed acid system with enhanced mechanical properties. Surfaces and Interfaces, 13, 46-50.

[32] Fariborz, A., Jahangiri, S., \& Pahnavar, Z. (2019). Thermodynamic and Electrochemical Investigations of Poly(Methyl Methacrylate-Maleic Anhydride) as Corrosion Inhibitors for Mild Steel in $0.5 \mathrm{M} \mathrm{HCl}$. Protection of Metals and Physical Chemistry of Surfaces, 55(6), 1161-1172.

[33] Mohammadi, M., Yazdani, A., Bahrololoom, M. E., \& Alfantazi, A. (2012). Corrosion behavior of 2024 aluminum alloy anodized in presence of permanganate and phosphate ions. Journal of Coatings Technology and Research, 10(2), 219-229. 